RECEIVED

JAN 26998

OSTI GA-A22706 CONF-971065--

\title{
ANALYSIS AND TESTING OF THE DIII-D OHMIC HEATING COIL LEAD REPAIR CLAMP
}

\author{
by \\ E.E. REIS, P.M. ANDERSON, E. CHIN, and J.I. ROBINSON
}

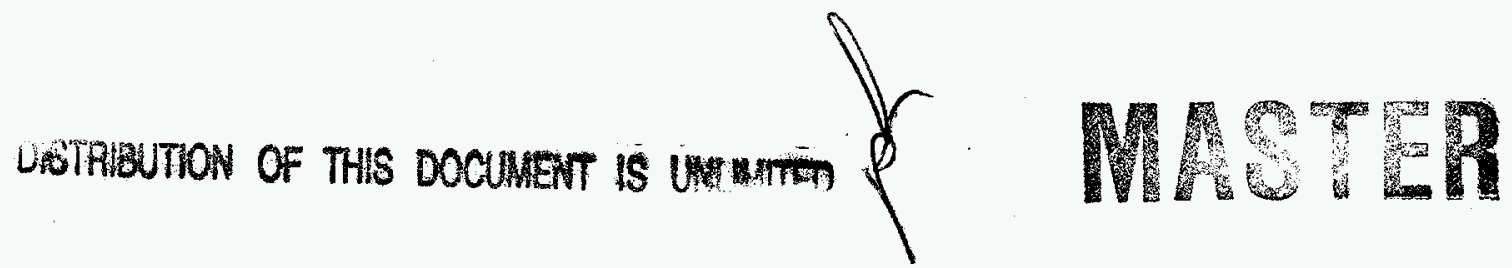




\section{DISCLAIMER}

This report was prepared as an account of work sponsored by an agency of the United States Government. Neither the United States Government nor any agency thereof, nor any of their employees, make any warranty, express or implied, or assumes any legal liability or responsibility for the accuracy, completeness, or usefulness of any information, apparatus, product, or process disclosed, or represents that its use would not infringe privately owned rights. Reference herein to any specific commercial product, process, or service by trade name, trademark, manufacturer, or otherwise does not necessarily constitute or imply its endorsement, recommendation, or favoring by the United States Government or any agency thereof. The views and opinions of authors expressed herein do not necescarily state or reflect those of the United States Government or any agency thereof. 


\section{DISCLAIMER}

Portions of this document may be illegible electronic image products. Images are produced from the best available original document. 


\title{
ANALYSIS AND TESTING OF THE DIII-D OHMIC HEATING COIL LEAD REPAIR CLAMP
}

\author{
by \\ E.E. REIS, P.M. ANDERSON, E. CHIN, and J.I. ROBINSON
}

This is a preprint of a paper to be presented at the 17th IEEE/NPSS Symposium on Fusion Engineering, October 6-11, 1997, San Diego, California and to be published in the Proceedings.

\author{
Work supported by \\ the U.S. Department of Energy \\ under Contract No. DE-AC03-89ER51114
}

GA PROJECT 3466

NOVEMBER 1997 


\title{
Analysis and Testing of the DIII-D Ohmic Heating Coil Lead Repair Clamp*
}

\author{
E.E. Reis, P.M. Anderson, E. Chin, and J.I. Robinson \\ General Atomics \\ P.O. Box 85608, San Diego, California 92186-9784
}

\begin{abstract}
DIII-D has been operating for the last year with limited volt-second capabilities due to structural failure of a conductor lead to one of the ohmic heating $(\mathrm{OH})$ solenoids. The conductor failure was due to poor epoxy impregnation of the overwrap of the lead pack, resulting in copper fatigue and a water leak. A number of structural analyses were performed to assist in determining the failure scenario and to evaluate various repair options. A fatigue stress analysis of the leads with a failed epoxy overwrap indicated crack initiation after 1000 cycles at the maximum operating conditions. The failure occurred in a very inaccessible area which restricted design repair options to concepts which could be implemented remotely. Several design options were considered for repairing the lead so that it can sustain the loads for $7.5 \mathrm{Vs}$ conditions at full toroidal field. A clamp, along with preloaded banding straps and shim bags, provides a system that guarantees that the stress at the crack location is always compressive and prevents further crack growth in the conductor. Due to the limited space available for the repair, it was necessary to design the clamp system to operate at the material yield stress. The primary components of the clamp system were verified by load tests prior to installation. The main body of the clamp contains a load cell and potentiometer for monitoring the load-deflection characteristics of the clamp and conductors during plasma operation. Strain gages provide redundant instrumentation. If required, the preload on the conductors can be increased remotely by a special wrench attached to the clamp assembly.
\end{abstract}

\section{INTRODUCTION}

The DIII-D tokamak was designed with two ohmic heating solenoids operating in parallel. One of the solenoids had to be shut down in May, 1995 when a water leak developed in one of the conductors in the lead pack. Inspection of the failed conductor was accomplished using borescopes. The length from the end of the lead pack to the crack location was thereby established. The leak was found to have developed in an area that is highly restricted by major coil systems and structures (Fig. 1). The crack in the copper conductor was seen from inside the coolant hole to extend over a 60 degree arc.

The lead pack consists of eight hollow conductors which are epoxy impregnated within a fiberglass overwrap as shown in Fig. 2. The electromagnetic forces on the individual conductors are self-reacting within the lead

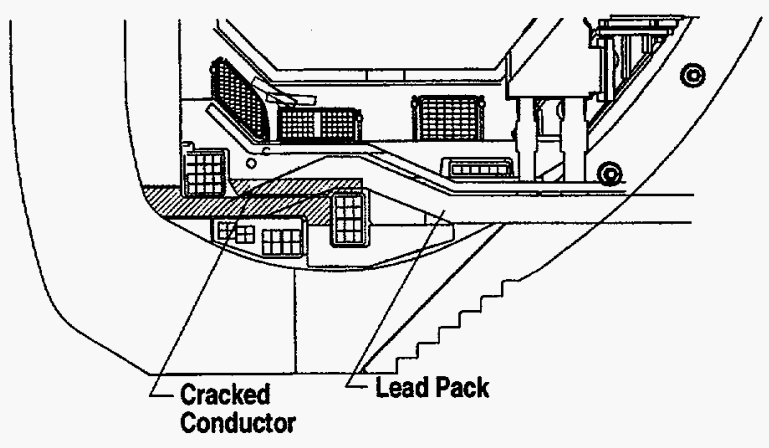

Fig. 1. Location of water leak in restricted area.

pack. Providing the overwrap remains intact, the stresses in the copper conductor and epoxy overwrap are relatively small compared to allowable values. It was therefore theorized that the overwrap failed, allowing high fatigue bending stresses to develop in the conductors. Special remote handling tools were used to remove the shrink wrap around the lead pack. Borescope inspection showed cracks in the fiberglass overwrap extending over a substantial length of the lead pack. Insertion of the borescope into the lead pack revealed dry fiberglass, confirming the theory that poor impregnation of epoxy during fabrication caused the failure of the top conductor of the lead pack.

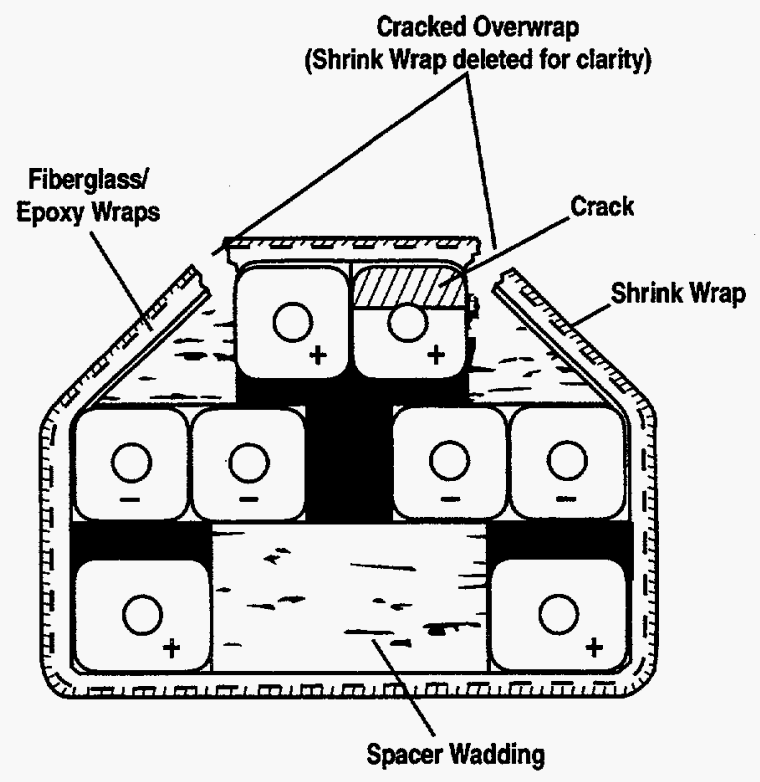

Fig. 2. Cross-section of lead pack at location of failure.

\footnotetext{
*Work supported by U.S. Department of Energy under Contract No. DE-AC03-89ER51114.
} 
It was estimated that disassembly of the machine to repair the leak would require more than one year of shutdown of operations. Although operations were able to continue with half of the solenoid, the experiments were limited to $5 \mathrm{Vs}$ shots with reduced flat top and less experimental flexibility during the ramp-up phase. Also, the peak plasma current as well as the number of piggy-back experiments was limited. The good half of the solenoid was being used to its full flux swing on every shot which increased the usage of its remaining fatigue life. These factors provided the motivation to proceed with investigations on how to remotely repair the failed lead pack with minimal impact on continued operations.

\section{FAILURE ANALYSIS}

Stress analyses were performed immediately after discovery of the water leak to assist in determining the failure scenario of the lead pack. The stress analysis of the pack as originally designed shows that the maximum stress in the conductor under $7.5 \mathrm{Vs}$ loads $(I=175 \mathrm{KA}$ in E-coil with $2.2 \mathrm{~T}$ full toroidal field) is only $20 \mathrm{MPa}$. This stress occurs near the interface of the leads with the ohmic heating solenoid.

The stresses within a properly fabricated lead pack at the cross-section where the leak occurred (Fig. 1) were analyzed using a 2-D plane strain structural model. Minimum material property data for overwrap and wadding were used to simulate a low density of fiberglass that may have been used during fabrication. The maximum stress in the overwrap at its failure location is only 1.1 MPa. The minimum shear fatigue stress for pure resin (no fiberglass is $3.5 \mathrm{MPa}$ at 100,000 cycles and represents a lower bound allowable shear stress. Therefore the lead would not have failed under these assumed conditions.

The 2D model was modified to simulate substantial debonding of the conductors within the overwrap. These analyses show that the overwrap would still be able to internally react the loads on the conductor. The maximum shear stress in the overwrap for the internally delaminated model was calculated to be $2.8 \mathrm{MPa}$. The lap shear fatigue strength of the overwrap exceeds $7 \mathrm{MPa}$.

The lead pack at the failure location in the conductor was therefore properly designed to react the maximum structural loads. These results indicate that either the lead pack was not properly fabricated or that the crack in the overwrap started elsewhere and propagated along the top of the failed conductor. Subsequent visual inspection indicates that the lead pack was not properly fabricated and that the initial crack probably started near the interface with the solenoid.

The fractures in the fiberglass overwrap at the location of the failed conductor are shown in Fig. 2. These fractures occur at the top of the lead pack and allow the top two conductors to deflect vertically upward and allow bending stresses in the upper conductors to exceed the yield stress of the copper. A fatigue stress analysis of the lead with the upper conductors unsupported over $50 \mathrm{~cm}$ was performed using the finite element beam model shown in Fig. 3. A conductor is assumed to be free to deflect vertically upward between the solenoid and the upper conductor bend. The forces within the remainder of the lead pack would result in a downward deflection. However, a G-10 block below the upper bend will prevent downward deflection and is therefore modeled as a simple support at the bend. The peak equivalent alternating fatigue stress occurs at the location of the crack in the conductor which is also the location of maximum deflection (Fig. 3). The fatigue curve for OFHC copper shows that a crack would be expected to start after about 1000 cycles at $200 \mathrm{MPa}$ corresponding to $7.5 \mathrm{Vs}$ operation.

Although the top two conductors were skip-welded together to assist in fabrication of the lead pack, only one conductor developed a water leak. Since both conductors are subjected to identical loads and are intermittently joined, one must assume that the conductor adjacent to the failed one also contains a crack. The lead conductors are fabricated from quarter hard OFHC copper, but were locally annealed around the vicinity of the skip welds during fabrication. It is likely that the crack was initiated in the conductor at one of the skip-welds and propagated to the coolant channel. A primary requirement in repair of the lead pack is to prevent further crack growth in both the failed conductor and, more importantly, the adjacent water-cooled conductor. The failed conductor lead will have limited cooling as presented in [1].

\section{ANALYSIS OF THE REPAIR CLAMP}

The approach taken to repair the failed lead pack utilizes the clamp system shown in Fig. 4 which provides

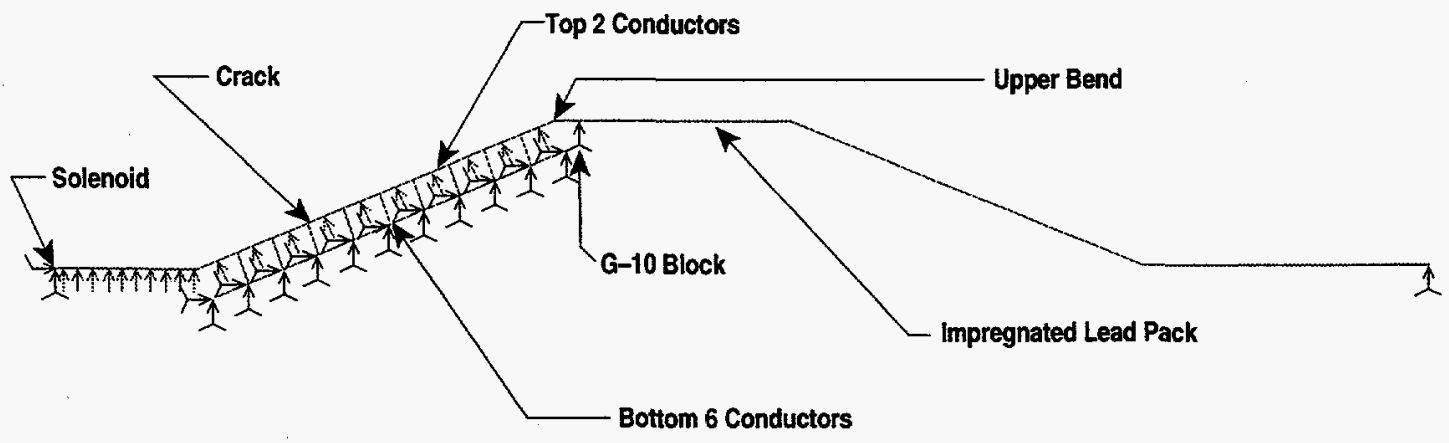

Fig. 3. Structural model for failed lead. 


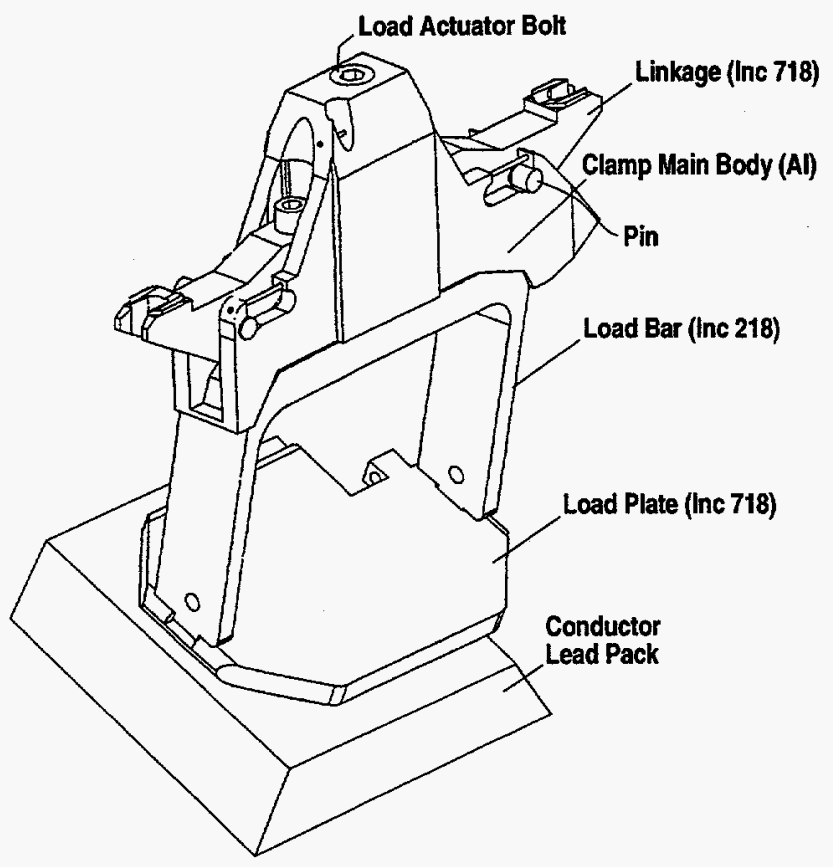

Fig. 4. Isometric of clamp.

sufficient preload to the failed lead that cracks in the top two conductors remain in compression under full operating conditions. The load on the clamp assembly was applied by the actuator bolt in the center of the load beam. The load is transmitted through a stack of Belleville washers, then through a $44,500 \mathrm{~N}$ load cell and into the load bar. The Belleville washers help maintain the preload after the creep relaxation of shim bags and other epoxy components. The load bar transfers the preload to the load plate, which is mounted over the cracked lead to restrain deflection of the lead under electromagnetic loads. The applied preload was measured by three parallel methods: (1) the calculated load from the applied bolt torque, (2) the load cell output, and (3) the output from strain gages mounted to the load plate.

The coolant channel of the cracked conductor was plugged and is conductively cooled by the adjacent conductor. To minimize the span of the unsupported conductor, the leads at the break-out from the solenoid are shim bagged and set in a large block epoxy. The upper horizontal section of the lead pack is also solidly supported top and bottom by shim bags and blocking. The outer section of the lead pack is clamped by metal straps that are also preloaded. A complete description of the repair and its installation is presented in [2].

The preload required to assure that stresses at the crack in the failed conductor and the probable crack in the adjacent conductor are always compressive was determined by modifying the boundary conditions to the structural model shown in Fig. 3. The shim bags and blocking reduce the unsupported length of the conductors to a known value of $32.6 \mathrm{~cm}$. The vertical electromagnetic loads on a conductor vary from $494 \mathrm{~N} / \mathrm{cm}$ at the inner shim bag to $375 \mathrm{~N} / \mathrm{cm}$ at the upper horizontal section. A vertical preload of $23 \mathrm{kN}$ near the crack location will prevent tensile stresses from developing at the tip of the crack. When the vertical field is reversed, the distributed loads on the conductors are acting in the same direction as the preload, resulting in higher compressive stresses at the crack. It is assumed that the fiberglass underneath the top conductors is not epoxy impregnated and therefore unable to self react the downward load within the lead pack. The bending stress for this load condition at the upper horizontal section of the conductor is less than the yield stress for quarter hard OFHC copper.

The main body of the repair clamp is fabricated from 7075-T6 aluminum because of its high strength and low weight. Weight was a consideration because the clamp had to be manually positioned by the finger tips of the technician. The clamp utilizes two linkages made from Inconel 718 which react the applied preload to existing bolted hardware that is normally used for securing a field shaping coil. The clamp preload stretches the bolts sufficiently that displacements of the field shaping coil during a shot will not affect the clamp assembly.

The structural model for the main body of the aluminum clamp is shown in Fig. 5. Symmetry boundary conditions are used to reduce to clamp to a one quarter model. The symmetry condition is approximate since one side of the clamp is slightly longer than the other. Tetrahedral elements with six degrees of freedom per node were used in the model. Due to the limited space available, the aerospace criteria of using the allowable bending stresses equal to the material yield stress (510 MPa) was adopted for design of the main body of the repair clamp. The 7075T6 aluminum has a minimum elongation to failure of eight percent.

The linkages for the clamp are Inconel 718 with a yield stress of $1035 \mathrm{MPa}$ and a minimum elongation to failure of 12 percent. The applied preload produces a total upward force of $41.6 \mathrm{MN}$ on the pins which is applied as triangular distributed forces along the small area underneath each pin.

The maximum stress intensities in each component of the repair clamp are presented in Table I. The maximum stress

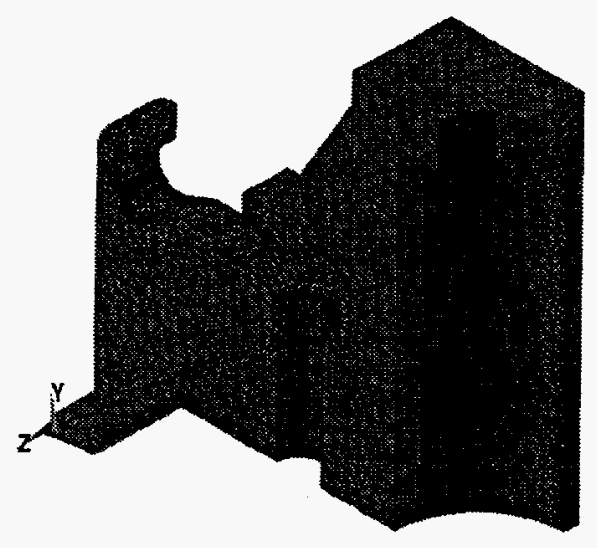

Fig. 5. FE model of clamp. 
Table I

Repair clamp stress summary

\begin{tabular}{llcc}
\hline \multicolumn{1}{c}{ Component } & \multicolumn{1}{c}{ Material } & Maximum Stress Intensity (MPa) & Allowable Stress Intensity (MPa) \\
\hline Main body of clamp & Aluminum 7075-T6 & 480 & 510 \\
Linkage arms & Inconel 718 & 490 & 1035 \\
Linkage pins & Inconel 718 & 930 & 1035 \\
Linkage bar & Inconel 718 & 490 & 1035 \\
Load plate & Inconel 718 & 300 & 1035 \\
\hline
\end{tabular}

intensity in the pin occurs at a location 90 degrees from the locations of the maximum bending stresses. If the pin were to be a press or shrink fit into the linkage, the additional radial compression stress due to the fit would be additive to the calculated stress. In addition, a stress concentration of about two would result by employing a press fit pin. Therefore, the pin was machined as an integral part of the linkage. The buckling factor of safety for the load bar is 34 against the operating load.

\section{TESTING OF THE REPAIR CLAMP}

Load tests were performed on each of the structural components of the preload system to 125 percent of the design working load. Separate tests were performed on the linkages, main body, load bar, and load plate. The components were then assembled and load tested to 125 percent of the design load as a system on a full size structural model of the lead mounted in a rigid test fixture. After testing, the clamp assembly was installed on DIII-D and the failed lead pack was preloaded to $23,130 \mathrm{~N}$. The preload was monitored by the load cell and load plate strain gages. The preload was periodically adjusted to compensate for creep effects by an in-situ cable actuated remote torquing system. Creep relaxation of the preload subsided after two weeks and no further adjustment has been required.

The load cell, strain gages, and a deflection potentiometer were monitored during the first plasma operations to determine the amount of pickup in the sensors due to the time varying magnetic fields. During this initial operation no current was present in the damaged lead and the clamp system has yet to be subjected to electromagnetic forces. The magnetic noise pickup was found to be fairly low on all three sensors, only about 1.0 to 3.5 percent. The damaged lead will be electrically connected for plasma operations in February, 1998. The clamp preload and deflection data will be monitored continuously at that time to verify that no excessive deflection of the lead occurs which could further damage the leads.

\section{CONCLUSIONS}

Structural analyses were performed to determine possible failure mechanism for the lead pack. The analyses concluded that extensive failure of the overwrap around the lead pack produced a fatigue crack in the conductor which eventually led to a water leak. Subsequent borescope inspections of the lead pack confirmed that overwrap had failed due to poor epoxy impregnation. Analysis of the proposed design for restoring the failed lead calculated the preload required to prevent further crack growth. Detailed stress analysis of the repair clamp system showed that the compact design of the main body and linkages would be highly stressed, but would be less than yield stresses for the selected materials. All components of clamp design were subjected to structural testing prior to installation. The repair clamp has been installed and the lead pack has been holding a constant preload since mid March 1997. Repair of the lead pack has restored 7.5 Vs capability to operation of DIII-D.

\section{REFERENCES}

[1] C.B. Baxi, P.M. Anderson, A.M. Gootgeld, "Thermal analysis and testing for DIII-D Ohmic heating coil repair," this conference.

[2] P.M. Anderson, J.I. Robinson, E. Gonzales, G.W. Relens, "Restoration of the DIII-D solenoid," this conference. 